\title{
Comparison of Three Phase Shunt Active Power Filter Algorithms
}

\author{
Charles.S, Member, IACSIT, G. Bhuvaneswari, Senior Member, IEEE.
}

\begin{abstract}
The use of active power filters is widely accepted and implemented as a solution to the power quality problems in utility, industry and commercial applications. In this paper, three of the three-phase shunt active filtering algorithms in time-domain have been compared for a non-linear load. The non-linear load chosen here is a soft-start for a three-phase induction motor. The comparison of the simulation results show the effectiveness of both the algorithms although the time domain current detection modified algorithm is more complex in terms of its implementation aspects.
\end{abstract}

Index Terms - Power quality, Shunt active power filter, Three-phase shunt active filtering algorithms, Performance comparison.

\section{INTRODUCTION}

The need for effective control and efficient use of electric power has resulted in massive proliferation of power semiconductor processors / converters in almost all areas of electric power such as in utility, industry, and commercial applications. This has resulted in serious power quality problems, since most of these non-linear converters contribute to harmonic injection into the power system, poor power factor, unbalance, reactive power burden, etc. all leading to low system efficiency. The vulnerability of equipments in automated processing industry to poor power quality leads to heavy losses. This resulted in the enforcement of stringent harmonic standards like IEEE 519 and IEC 61000-3.

Among the various options available to improve power quality, the use of active power filters is widely accepted and implemented as a more flexible and dynamic means of power conditioning [1-2]. These shunt active power filters and series active power filters are basically pulse width modulated (PWM) current source inverters (CSI) and voltage source inverters (VSI), respectively. The drawbacks of the conventional passive filters such as huge size, problems associated with resonance, dependency on source impedance and fixed compensation. The hybrid filters combine passive and reactive filters reducing the effective cost.

The active power filter is expected to generate the appropriate compensating voltage / current signals that

Manuscript received June 13, 2009.

Charles. S, Lecturer, Department .of Electrical Engineering, Sri Shakthi Institute of Engineering and Technology, Coimbatnore-641014, India. Phone: 9659478930::email: charlesme@gmail.com.

G. Bhuvaneswari, Associate Professor, Department of Electrical Engineering, Indian Institute Tehnology, NewDelhi-110016, India. email: bhuvan@eee.iitd.ac.in cancel the harmonic and reactive power components in the voltage / currents from the mains. The reference compensation signals are generated by making use of a control algorithm. The

Instantaneous PQ theory by Akagi [3] and the synchronous detection method [4] are two of the most widely used control algorithms for three-phase shunt active power filters. There have been several published papers on various time-domain based shunt active filtering algorithms [5, 6]. In [7], a modification of Instantaneous Reactive Power Theory (IRPT) in conjunction with Discrete Fourier Transform (DFT) has been proposed to extract the reference compensation currents. In all the above mentioned algorithms, the computation steps and the circuits involved remain complex. In this context, the authors had proposed a new, simple, three-phase, shunt active power filter algorithm [10]. In this paper, the proposed algorithm which is known as Icos $\Phi$ algorithm is compared with the Time-Domain Current Detection (TDCD) algorithm [8], Synchronous Reference Frame Theory (SRF) [9] especially for an AC voltage controller feeding an induction motor while the motor is being started. The simulation results have been presented for both the algorithms to compare the effectiveness and simplicity of one over the other.

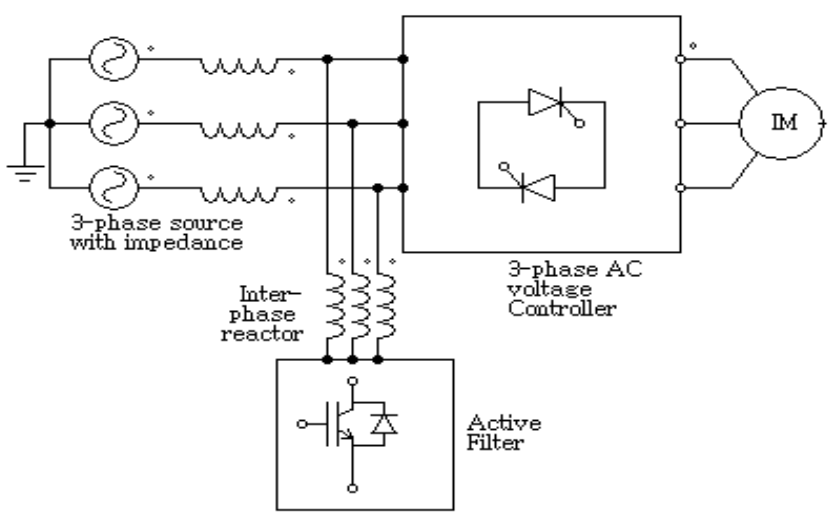

Figure1 Three-phase system feeding a non-linear load

\section{Time Domain CURREnT Detection Algorithm}

In this section, the TDCD algorithm for shunt active filter has been described. The working of this algorithm is as follows: Let the three-phase non-linear load connected to the system draw harmonic rich unbalanced currents from the three-phase source as shown in Fig.1. The three-phase load 
currents are first sensed and the algorithm first detects only the positive sequence current component. As the sequence currents only involve the power frequency component, the harmonic components are eliminated automatically. From this positive sequence current, the real and reactive components are separated out. The real component of the positive sequence current is designated as the reference source current. The difference between the reference source current and the actual load current is computed as the reference compensation current which is to be supplied by the active filter. This ensures that the source currents become balanced and also purely sinusoidal unity power factor currents. The Block diagram of Time Domain Current Detection algorithm is shown in Fig 2.

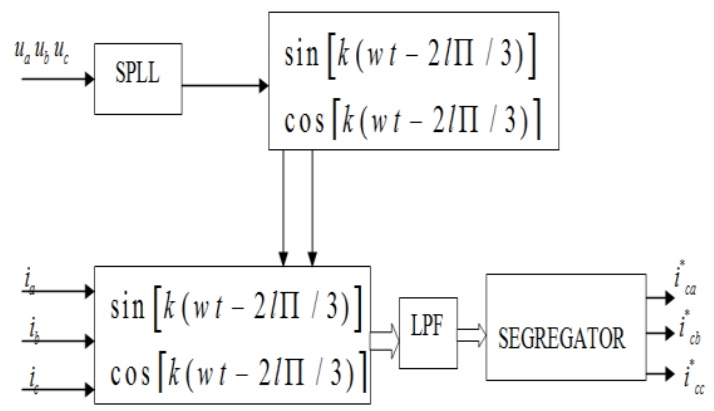

Figure2 Block diagram of Time Domain Current Detection algorithm

\section{Synchronous RefEREnce Frame D-Q-0 BASED COMPENSATION}

Synchronous Reference Frame (D-Q-O) having measured three-phase load currents in a-b-c orientation, transformed to d-q-o by park equation:

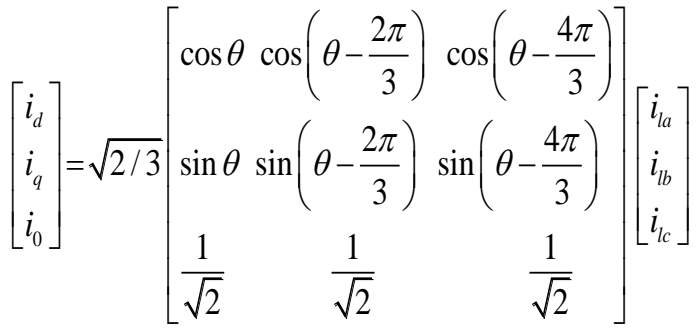

Reference frame rotates synchronous with fundamental currents. Therefore, time variant currents with fundamental frequencies would be constant after transformation. However,

harmonics with different speeds remain time variant in this frame. Thus, currents would be separate simultaneously to $\mathrm{DC}$ and $\mathrm{AC}$ parts.

$\mathrm{AC}$ part of $\mathrm{d}$ axis and whole current in $\mathrm{q}$ axis are used for harmonics elimination and VAR compensation. Zero current is produced due to a three-phase voltage imbalance or waveform distortions which have not been considered in this paper. Finally, compensated currents are determined by adverse park application on $\mathrm{d}$ and $\mathrm{q}$ axis to be injected to the network after tracing and reconstruction.

\section{DESCRIPTION OF I.COS $\Phi$ Algorithm}

Any control scheme for the shunt active filter ensures that the current drawn from the mains is purely sinusoidal and in phase with the mains voltage i.e. at unity power factor supplying only the active part of the required load current. In the I. $\cos \phi$ algorithm, the desired mains current is hence assumed to be the product of the magnitude of the real component of fundamental load current (I. $\cos \phi)$ and a unity sinusoidal wave in phase with the mains voltage.

The magnitude I.cos $\phi$ is deduced as the magnitude of the fundamental component of the active part of the load current where ' $\mathrm{I}$ ' is the amplitude of the fundamental component of load current and ' $\cos \phi$ ' is the displacement power factor of the load. The three-phase mains voltages are used as templates to generate unit amplitude sine waves in phase with mains voltages. A multiplier is used to derive the desired mains current as the product of the magnitude I. $\cos \phi$ and the unit amplitude sinusoidal wave in phase with the mains voltage. The reference compensation currents for the shunt active filter are thereafter computed as the difference between the actual load currents and the desired mains currents for the three phases. The schematic diagram of the I. $\cos \phi$ control algorithm is shown in Fig.3.

The voltage fluctuations at the DC bus capacitor of the filter are used to calculate the extra power loss in the inverter and the interface transformer. The corresponding current amplitude is calculated and added to the active component of the fundamental load current in each phase i.e. to the I. $\cos \phi$ component. This ensures that the losses in the active filter are being taken care of by the three-phase source and the DC bus of the active filter becomes a self-supporting one. Under balanced voltage condition, the unit sine wave voltage templates are directly generated from the respective phase voltages using non- inverting amplifier circuits with suitable gains. Under unbalanced voltage condition also the unit sine wave voltage templates are directly generated from the respective phase voltages using non-inverting amplifier circuits with suitable gains. Here, the only difference is that the gains of the non-inverting amplifier circuits are to be suitably changed depending on the unbalance in the phase voltages. In case of distorted mains voltages, the fundamental components of the mains voltages are extracted using second order low pass filters tuned to fundamental frequency and used as the templates.

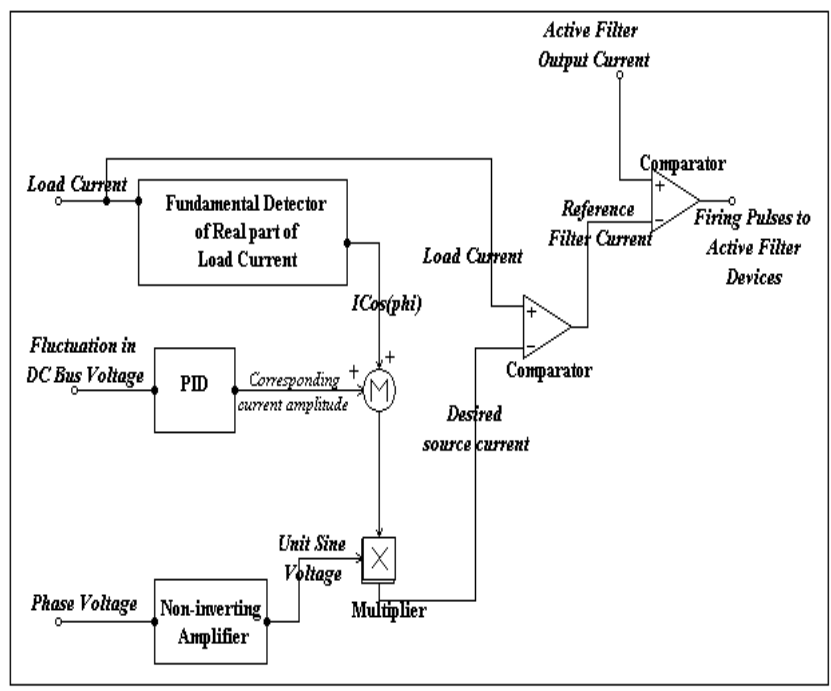


Figure3 Block diagram of the I.cos $\phi$ control circuit.

\section{Simulation of Shunt Active Filtering Algorithms}

This section describes the simulation models created for TDCD algorithm, Synchronous Reference Frame (SRF) theory and I. $\cos \phi$ algorithm in SIMULINK/MATLAB environment.

\section{A. Simulation of TDCD Algorithm}

The simulation model for the TDCD algorithm is shown in Fig.4. As described earlier in Section II, the sequence currents are detected from the load currents using sequence analyzer lock existing in the "Simpowersystems" toolbox of MATLAB.

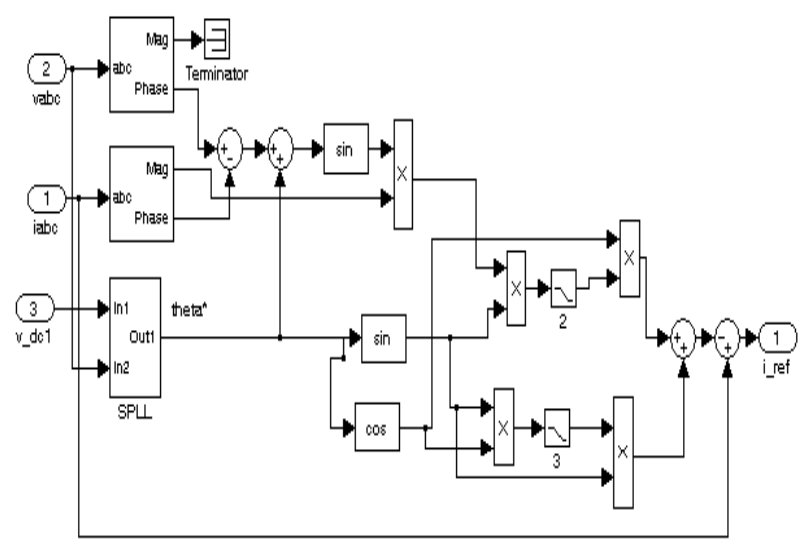

Figure4 Simulation Model for TDCD algorithm

Then, the power factor angle is deduced by determining the phase-shift between positive sequence voltages and currents. Using sine and cosine blocks and the power factor angle, the real and reactive components of the positive sequence currents are separated out. The difference between the real component of the positive sequence current and the load current yields the reference compensation current to be supplied by the shunt active filter.

\section{B. Simulation of SRF Theory}

As described earlier in Section III, the three phase load currents in a-b-c orientation, transformed to d-q-o by park equation. $\mathrm{D}$ axis current $\left(\mathrm{i}_{\mathrm{L}} \mathrm{d}\right)$ is filtered out and applied to inverse transformation to remove DC component and to determine harmonic contents. $\mathrm{Q}$ axis current $\left(\mathrm{i}_{\mathrm{L}} \mathrm{q}\right)$ is applied to inverse transformation to compensate reactive power. 0 axis current $\left(i_{L} 0\right)$ must be used when the voltages are distorted or unbalanced and sinusoidal current are desired. The DC side voltage of APF should be controlled and kept at a constant value to maintain the normal operation of the inverter. The simulation model for the SRF theory is shown in Fig.5

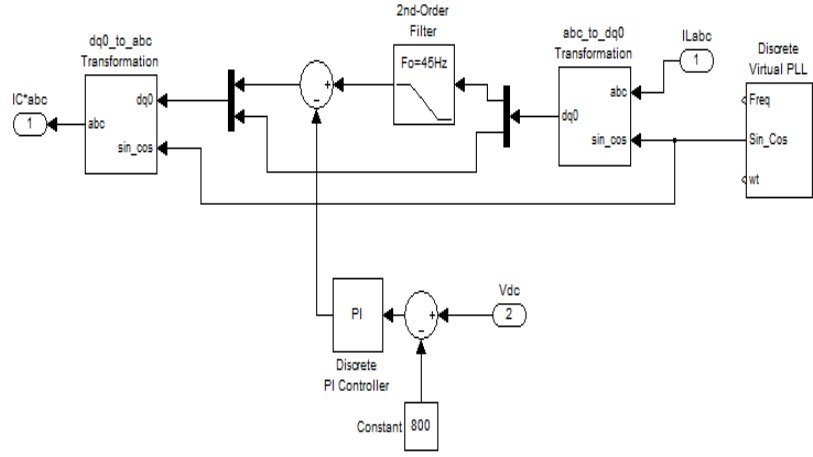

Figure5 Simulation Model for SRF Theory

\section{Simulation of Icos $\Phi$ Algorithm}

The block diagram of the control circuit given in Fig.3 explains how the control circuit generates the reference compensation currents for the I. $\cos \Phi$ algorithm. The I. $\cos \phi$ value is deduced as the magnitude of the fundamental component of the active part of the load current. This is extracted using Fourier blocks tuned to the fundamental frequency. The voltage fluctuations at the DC bus capacitor of the filter are used to calculate the extra power loss in the inverter and the interface transformer. The corresponding current amplitude is calculated using a suitably tuned PID controller and added to $t$ active component of the fundamental load current in each phase to a ensure self Support DC bus

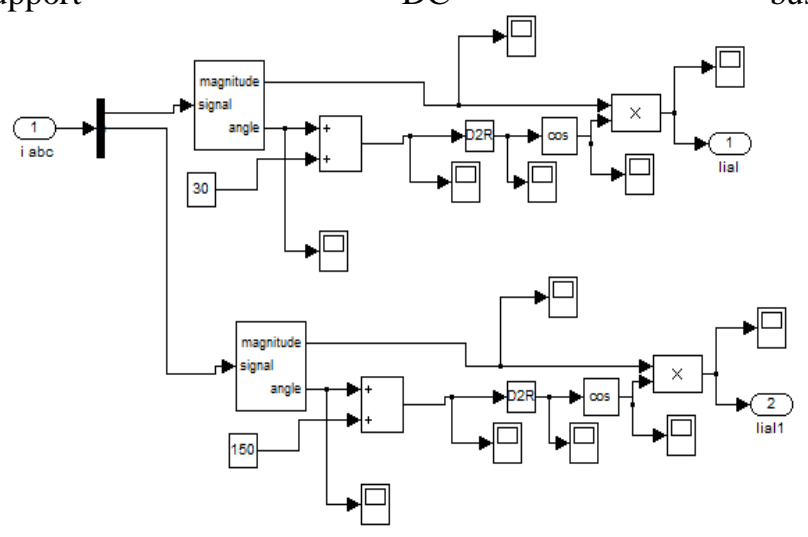

Figure6 Simulation model of I cos $\phi$ Algorithm

for the active filter. Since an AC voltage controller load with a large delay angle is considered here, the displacement power factor $\cos \phi$ becomes small and hence the magnitude I. $\cos \phi$ will be much less than the fundamental current magnitude I.

The three-phase mains voltages are used as templates to generate unit amplitude sine waves in phase with mains voltages. A multiplier is used to derive at the desired mains current as the product of the magnitude of real component of fundamental load current (I.cos $\phi$ ) and the unit amplitude sinusoidal wave in phase with the mains voltage. The reference compensation currents for the shunt active filter are thereafter computed as the difference between the actual load currents and the desired mains currents for the three phases. Fig. 6 depicts the simulation diagram I.cos $\phi$ algorithm. 


\section{COMPARISON OF SIMULATION RESULTS}

The analysis of the three-phase system given in Fig.1 has been done in SIMULINK/ MATLAB environment. The system has a 3-phase AC source of $415 \mathrm{~V}$ at $50 \mathrm{~Hz}$ feeding a 3 -phase induction motor of $22 \mathrm{~kW}$ rating through an $\mathrm{AC}$ voltage controller

The A phase source voltage and three phase load currents are shown in Fig.7 for the AC voltage controller feeding an induction motor. The three phase voltages and source currents after compensation are shown in Fig.8, 9 and10 respectively for the TDCD algorithm, SRF theory and the I $\cos \Phi$ controller.

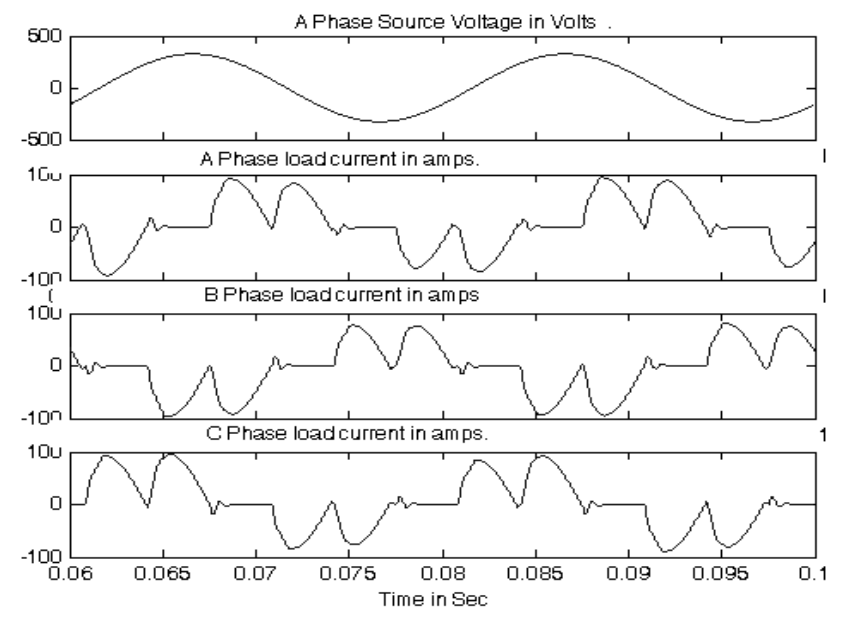

Figure7 A Phase source voltage and three-phase load currents at a firing angle of $115^{\circ}$ of the AC Voltage controller

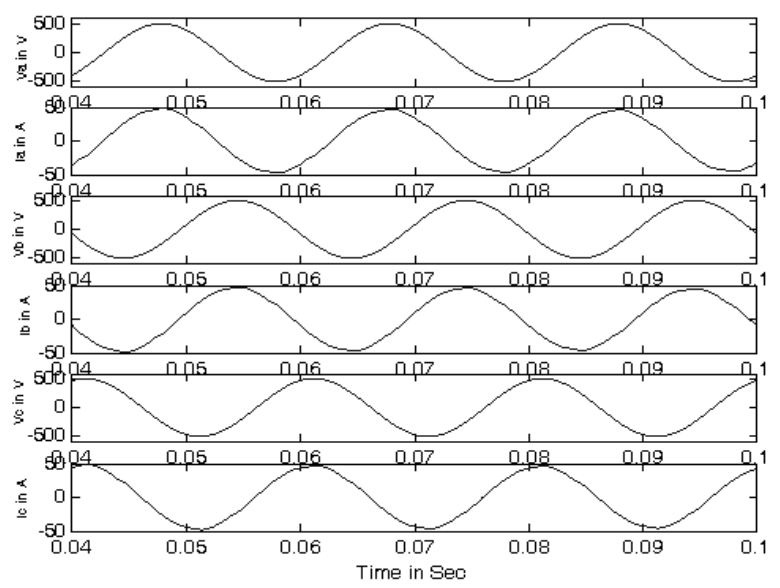

Figure8 Three phase source voltages and currents after compensation in TDCD algorithm

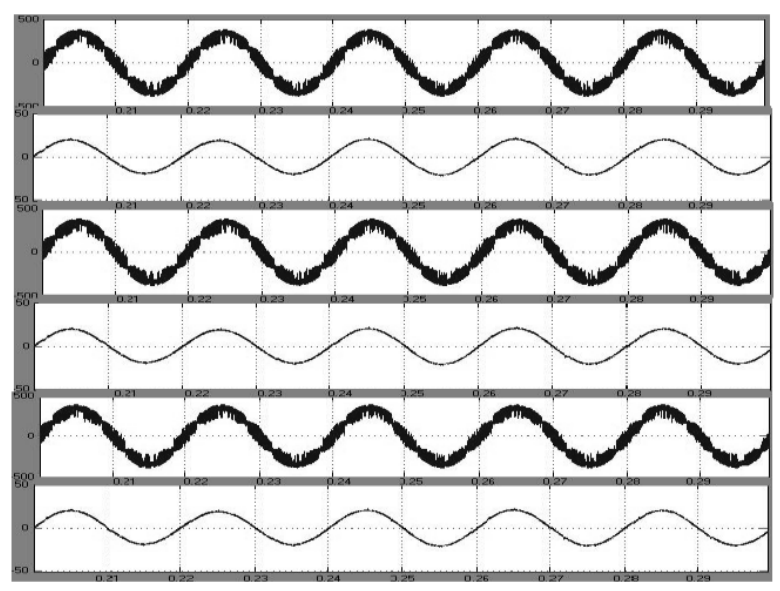

Figure9 Three phase source voltages and currents after compensation in SRF Theory

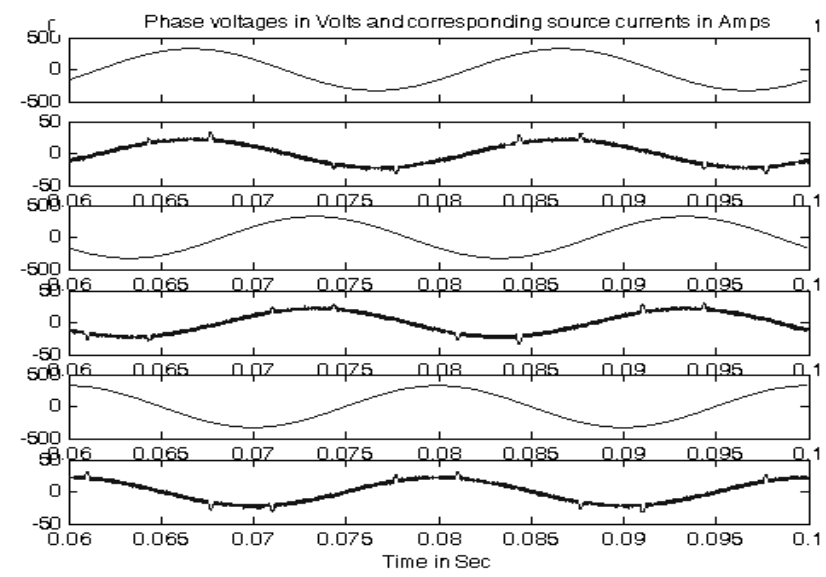

Figure10 Three phase source voltages and currents after compensation in Icos $\Phi$ algorithm

The mains currents in the three phases after compensation are expected to be purely sinusoidal and in phase with the mains voltages. The results obtained for all the three phases for both the above-mentioned control algorithms show that the shunt compensation has been achieved fairly well in both cases. The FFT analysis (Figs. 11,12 and 13) of the source currents before and after compensation in the two cases show that the harmonics decrease drastically from about $54 \%$ to less than 5\% after compensation in all the cases.

Table1 lists the \%THD of the mains current before and after shunt compensation based on the three control schemes.

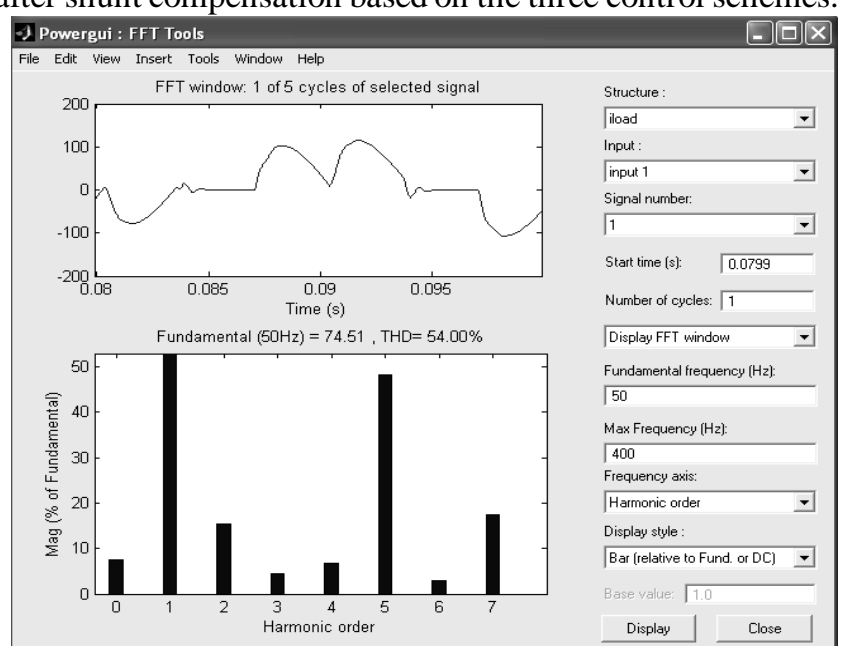


Figure11 THD in A phase load current

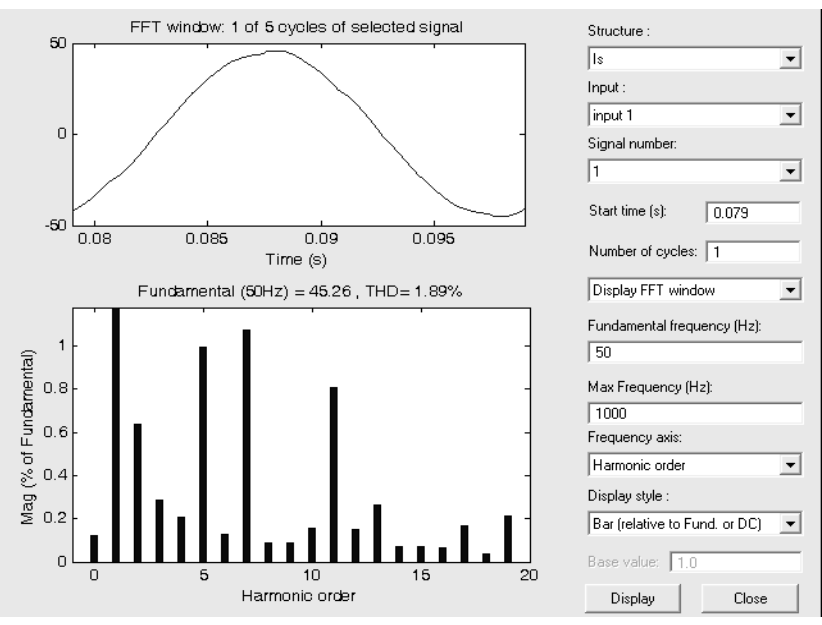

Fig.12 THD in source current after compensation using TDCD algorithm

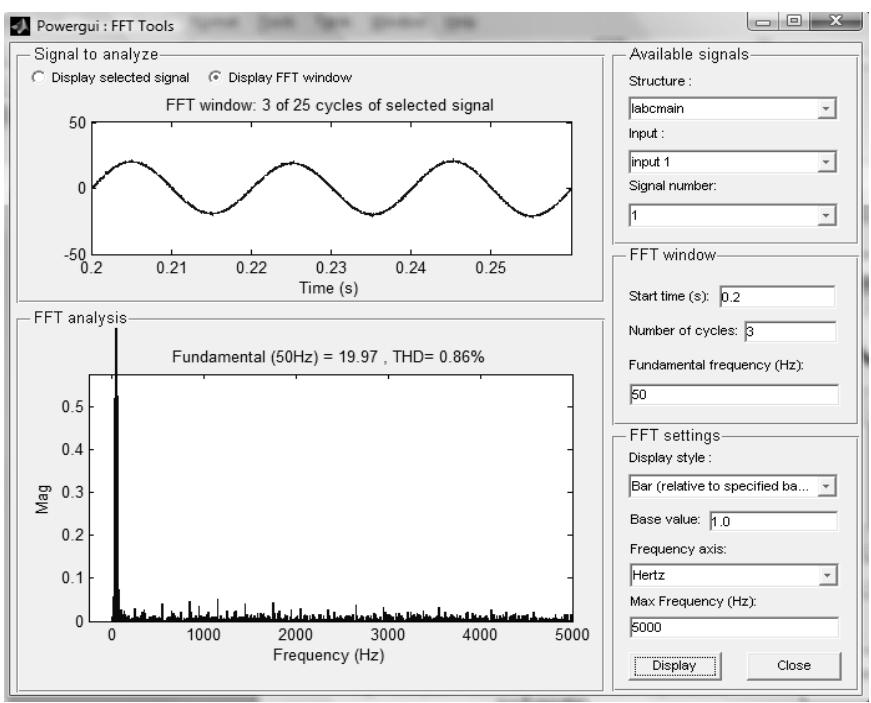

Fig.12 THD in source current after compensation using SRF Theory

Although TDCD algorithm and SRF theory yields better results in terms of THD of compensated source current, the complexities involved in the implementation of this algorithm discourages the use of this in real-time. In comparison, the I.cos $\Phi$ controller is much simpler to implement in hardware.

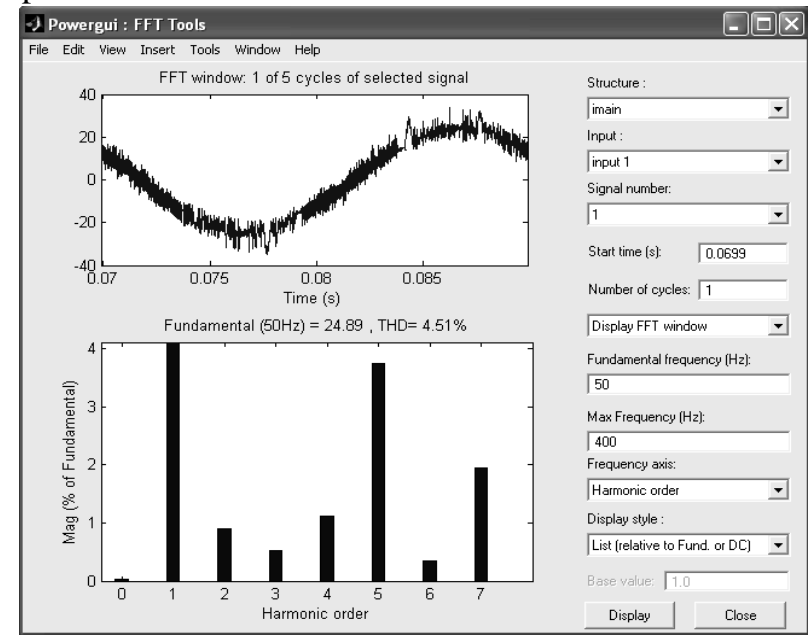

Figure12 THD in source current after compensation using Icos $\phi$ Algorithm

\begin{tabular}{|l|c|}
\hline \multicolumn{1}{|c|}{ METHOD USED } & \% THD \\
\hline Before any shunt compensation & $54 \%$ \\
\hline Modified IRPT algorithm & $1.8 \%$ \\
\hline $\begin{array}{l}\text { Synchronous Reference Frame } \\
\text { Theory }\end{array}$ & $0.86 \%$ \\
\hline I cos $\Phi$ Algorithm & $4.5 \%$ \\
\hline
\end{tabular}

TABLEI. 1: \% THD IN THE SOURCE CURRENTS AFTER COMPENSATION

\section{CONCLUSIONS}

In this paper, two time-domain based shunt active filtering algorithms have been analyzed and studied in SIMULINK/MATLAB environment. A three-phase balanced supply feeding a soft-start for an induction motor is simulated with a shunt active power filter based on these two control schemes. Comparison of the Time Domain Current Detection algorithm and I.cos $\Phi$ algorithm brings out the following:

(i) The computational steps and circuits involved are drastically decreased in the proposed Icos $\Phi$ algorithm.

(ii) Fairly sinusoidal, unity power factor mains currents are generated by both the control schemes. However, the TDCD algorithm involves sequence analyzer which calls for complex calculations.

(iii) SRF controller such as non-unity gain has been effectively addressed by a inverter output voltage feedback loop significantly enhances the performance of SRF controller.

The I. $\cos \Phi$ algorithm is applicable in all cases of three phase systems such as balanced, unbalanced and distorted source voltages and non-reactive as well as reactive non-linear loads. The results presented here prove the effectiveness of the algorithm when the load is a non-linear, reactive load.

\section{REFERENCES}

[1] S. Rahmani, K. Al-Haddad \& F. Fnaiech, "A three- phase shunt active power filter for damping of harmonic propagation in power distribution networks", Proc. IEEE International symposium on Industrial Electronics, vol. 3, pp. 1760-1764, July 2006

[2] B.N.Singh et.al., "Design and Digital Implementation of Active Filter with Power Balance Theory", IEEE Proc on EPA, Vol 2, No.5, Sept 2005 pp.1149-1160

[3] H. Akagi, Y. Kanazawa \& A. Nabae, "Instantaneous reactive power compensators comprising switching devices without energy storage components," IEEE Trans. Industry Applications, vol. 20(3), pp. 625-630, 1984.

[4] C.L. Chen, C.E. Lin \& C.L. Huang, "Reactive and harmonic current compensation for unbalanced three-phase systems using the synchronous detection method," Electric Power systems Res.., vol 26, pp163-170, 1993.

[5] Bor-Ren Lin et.al., "Analysis and operation of hybrid active filter for harmonic elimination" Electric Power Systems Research 2002, Vol.62, pp.191-200. 
[6] H. L. Jou, "Performance comparison of the three-phase-active-power-filter algorithms," in Proc. IEE Conf. On Generation, Transmission, Distribution, pp. 646-652, 1995.

[7] S. Bhattacharya \& D. Divan, "Synchronous frame based controller implementation for a hybrid series active filter system," in Proc. 13th IAS Annual meeting, pp. 2531-2540, 1995.

[8] H.Li, F.Zhuo, Z.Wang, W.Lei and L.Wu "A Novel Time-Domain Current-Detection Algorithm for Shunt Active Power Filters" IEEE Trans on Power Systems, Vol.20, No.2, May 2005. Pages: 644-651.

[9] D.Basic, V.S.Ramesdan, P.Mutik, "Digital Implementation of the Synchronous Frame Based Controller for a Selective Hybrid filter control system ", in Proc IEEE Confe,2007

[10] G.Bhuvaneswari \& M.G Nair, "A novel current compensation technique for shunt active power filters", in Proc. IASTED Conf On Power and Energy Systems, PP . 109-113,2003

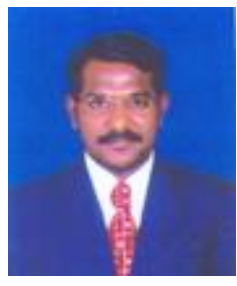

Charles S obtained his B.E. degree (2004) in Electrical and Electronics Engineering and his M.E. (2006) in Power Electronics and Drives from Anna University, India. Currently, he is a Lecturer in the Dept of Electrical and Electronics Engineering, Sri Shakthi Institute of Engineering and Technology, Coimbatore,Tamilnadu. India. His area of interest is Active Power Filters, Power Electronics, and Power Quality.

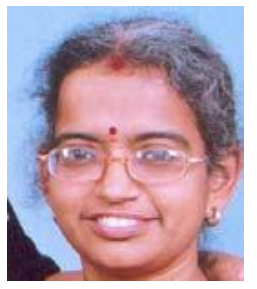

G.Bhuvaneswari obtained her Masters and doctoral degrees from the Department of Electrical Engineering, IIT, and Madras, India. She was working as a faculty member in Anna University for about 2 years and subsequently she was with the Electrical utility ComEd. Since 1997 she has been Working as a faculty member in the Department of Electrical Engineering, IIT, Delhi where she is an Associate Professor now. She is a Senior Member of IEEE and a Life Fellow of IETE. Her areas of interest are Power Electronics, Electrical Machines, Drives and Power Quality. 